\title{
Sólo la verdad nos hará libres: "La necesidad de investigar para consolidar la enseñanza universitaria”
}

\author{
MBA Gloria LÓPEZ RIVAS ${ }^{18}$
}

\section{RESUMEN:}

Este artículo trata sobre la necesidad de "investigar" como una estrategia para adquirir y profundizar en el conocimiento que tengamos, en la disciplina que nosotros practiquemos. Esta tarea nos conduce a consolidar nuestra enseñanza y aprendizaje de la disciplina que practiquemos, al escudriñar sobre la teoría y confrontarla con la realidad.

PALABRAS CLAVE: Investigación, Universidad, Profesor, Enseñanza, Aprendizaje.

\section{ABSTRACT:}

This article deals the need to "investigate" as a strategy to acquire and deepen the knowledge we have, in the discipline that we practice it. This task leads us to consolidate our teaching and learning of the discipline to practice, to examine and confront the theory with reality.

KEY WORDS: Research, University, Professor, Teaching, Learning.

\section{INTRODUCCIÓN}

Las reflexiones siguientes presentan una visión para el trabajo académico y proveen algunas pautas de acción para su futuro desempeño. Se basan en la sencilla pero profunda propuesta que hizo el maestro divino, "Cristo", quien instruyendo a sus discípulos sobre cómo enfrentar la misión que les había dado les dijo: "Solo la verdad los hará libres". Ellos se inquietaron por la rotundidad de esta máxima. Desde entonces ella ha resonado en los oídos de todo hombre que busca, en particular de ser maestro.

El maestro de aula y sus alumnos deben caracterizarse por que buscan y porque dudan ya que si no buscan y no dudan nunca despertaran a la verdad. Como dijera el filósofo Descartes:" Dudo porque pienso, y si pienso es porque existo".

18 Cualquier consulta favor de escribir: edme.lopez@gmail.com 
La pertinencia de esta frase es actualmente mayor que nunca para el mundo académico, no solo porque guía toda enseñanza sino como asidero para toda investigación y como estímulo para el comportamiento moral de todo investigador.

Esta máxima será reflexionada en este artículo para proveer de asidero a la diaria labor de Enseñanza/Aprendizaje, para marcar guías de acción a los investigadores y dar ciertos lineamientos de decisión a los acreditadores.

\section{2. ¿QUÉ ES LA VERDAD?}

Es asunto esencial de la filosofía habiendo sido durante siglos objeto de estudio y debate por parte de filósofos, científicos, historiadores, religiosos, legisladores, poetas, etc. No es mi intención acá abrir un debate, aunque existe la necesidad ineludible de dejarnos guiar por esta máxima entendiendo claramente su significado. La verdad es una categoría eidética, de valor, que para los administradores tiene una connotación cuestionadora, ya que nos invita a la autocrítica, a preguntarnos:

- ¿Conozco realmente mi materia?

- ¿Estoy interesado(a) en los cambios que esta materia está experimentando actualmente en el mundo?

- ¿Puedo con el apoyo de la tecnología de hoy llegar a descifrar toda o al menos buena parte de lo que comprende este campo del conocimiento?

- ¿Qué implica para el Perú, para la empresa y para la universidad, para mis alumnos jóvenes, este estado del avance de mi campo de conocimiento?

- ¿Qué debo hacer al respecto? ¿Cómo y dónde encontrar el conocimiento que nos lleve a desempeñar la realidad?

Cualesquiera que sean las respuestas personales que logremos, nos confrontaremos en el hecho que el mundo de hoy 2015 posee un complejo escenario científico, cultural, social económico y político totalmente distinto al hace un año, y mucho más al de hace 10, 20 o 30 años, que prevalecía cuando accedimos a la hermosa tarea docente.

De otro lado, debido a la variedad infinita de experiencias, especialmente en el Campo de los negocios, donde un mismo problema puede ser abordado por diversas mentes en infinitas formas, no hay la "verdad", sino una "verdad", que es el punto de vista del que resuelve cada situación problemática.

\section{LA VERDAD ACADÉMICA SE LOGRA INVESTIGANDO}

Se lee en los fines de la universidad que, ella es el ente que da luz, guía, provee pautas, y direccionalidad a la sociedad en el supuesto que toda universidad es la "casa del saber" donde se busca y se encuentra la "verdad" y luego se la difunde. Esta búsqueda de conocimiento es tarea medular del quehacer universitario, ya que la realidad que enmarca cualquiera de los campos o facetas del saber es dinámica, cambiante y en consecuencia nos sobrepasa a todos desafiándonos a actualizarnos en forma permanente o salir de la Competencia. 
Solo el que investiga concienzudamente, día tras día, podrá al menos intuir lo que pasa en su materia. O campo de especialidad. "Solo investigando el profesor estará en capacidad de entender los cambios, y de ir a la par de estos y/o de prever el futuro. El que no investiga solo será un mero repetidor de conocimientos ajenos, quizás no adecuados a nuestra realidad, a nuestro contexto, a nuestra gente, o podría caer en el estancamiento, en el desfase de su rama de especialización". Solo investigando, hurgando en la realidad que cambia y que a todos nos preocupa es que llegaremos a la "verdad" aunque sea a un reflejo pálido de esta. En lo que respecta a la tarea de Acreditación, esta máxima supone que no es cuestión de calificar para aprobar un conjunto de estándares sino de acceder a dicho reconocimiento proveyendo información fidedigna respecto al cumplimiento de dichos estándares. La consecuencia de este trabajo -en el que todos debemos involúcranos- será que algunos tengan que modificar radicalmente sus planes de trabajo y desarrollo de investigación. . Por ejemplo, se deberán de demostrar que los nueves estándares de Calidad (del 47 al 55) que el CONEAU ha establecido, respecto a la Investigación efectivamente se han logrado en la realidad.

Este será el desafío de convocar a todos los profesores de cada carrera a internalizar dentro de sus estrategias de Enseñanza y Aprendizaje, al MÉ TODO CIENTÍFICO. Al integrar este paradigma de la investigación en la matriz de estrategias de enseñanza y aprendizaje estaremos contribuyendo a formar desde sus bases no solo aptitudes sino también actitudes de investigación en los alumnos. De esta manera se pondrán las bases para la Investigación Formativa y se forjara una masa crítica de investigadores, tanto profesores como alumnos, que puedan generar y evaluar con propiedad Proyectos de Investigación de Calidad.

EL segundo reto es organizacional y considero que se afrontara dándole al IESEMA-FACEE la autoridad y recursos para que dirija la definición de las Líneas de Investigación, con los responsables de cada escuela, estimule la formación de Grupos de Investigación que se aboquen a investigar proyectos concretos sea por área académica o por línea de Investigación.

Un Tercer desafío será la búsqueda de recursos financieros para sostener la inversión que requiere toda investigación. Por el momento una fuente más rápida es el FINCYT. Pero a mediano plazo será indispensable acceder a Fundaciones internacionales, Agencias de Cooperación Nacional y Extranjeras y a forjar Alianzas estratégicas con las Empresas. Un Adelanto de las pautas que acabo de plantear se resume en el cuadro siguiente: Nueva Visión de la Investigación en la FACEE, por líneas, grupos de Investigación y fuentes tentativas de recursos. Al respecto es posible inspirarnos en las estrategias llevadas a cabo por otras Universidades que lideran la investigación, especialmente en Ciencias duras y Ciencias Sociales. 
Tabla $\mathbf{N}^{\circ}$ 1: Ejemplo de la investigación en la enseñanza aprendizaje, Se plantea que cada profesor consolide su enseñanza de la materia con investigación como instrumento estratégico del aprendizaje. Se puede observar la interrelación entre la teoría del curso y sus aplicaciones en proyectos, trabajos y desarrollo de casos, etc.

\begin{tabular}{|c|c|c|c|}
\hline $\begin{array}{l}\text { ESCUELAS } \\
\text { DE LA FACEE }\end{array}$ & $\begin{array}{l}\text { LÍNEAS DE } \\
\text { INVESTIGACIÓN }\end{array}$ & GRUPOS & $\begin{array}{l}\text { TRABAJOS O } \\
\text { PROYECTOS }\end{array}$ \\
\hline $\begin{array}{l}\text { Administración } \\
\text { y Gerencia }\end{array}$ & $\begin{array}{l}\text { - Problemas de Gestión } \\
\text { Ambiental Empresarial } \\
\text { - Diagnóstico de Gestión } \\
\text { Integral del Agua, Rie- } \\
\text { go y sistemas ecológi- } \\
\text { cos en Santa Eulalia. } \\
\text { - Potenciación de los } \\
\text { recursos naturales por } \\
\text { transformarlos en Pro- } \\
\text { ductos terminados de } \\
\text { Alta demanda en el mer- } \\
\text { cado de Lima. }\end{array}$ & $\begin{array}{l}\text { - Taller de Investigación Apli- } \\
\text { cada: Seminario de Tesis } 1 . \\
\text { - Taller de Investigación Apli- } \\
\text { cada: Seminario de Tesis II } \\
\text { - Curso de Marketing: Planes } \\
\text { de Marketing sobre: } \\
\text { - Galletas de Guanábana } \\
\text { - Batidos de Camú Camú. }\end{array}$ & $\begin{array}{l}\text { - Como mejorar el clima } \\
\text { laboral recuperando las } \\
\text { áreas Ecológicas de Pro- } \\
\text { segur. } \\
\text { - Causas que obstruyen la } \\
\text { apertura del Centro de } \\
\text { Acopio en Callahuanca } \\
\text { - Activos Culturales para } \\
\text { lograr inclusión de Jóve- } \\
\text { nes. }\end{array}$ \\
\hline $\begin{array}{l}\text { Contabilidad y } \\
\text { Finanzas }\end{array}$ & & $\begin{array}{l}\text { Curso de Administración de } \\
\text { Empresas }\end{array}$ & $\begin{array}{l}\text { Elaboración de Casos Reales sobre } \\
\text { Gestión de la Pequeña Empresa }\end{array}$ \\
\hline
\end{tabular}

Fuente Propia

\section{CONCLUSIONES:}

1. El maestro de aula y sus alumnos deben caracterizarse porque buscan la investigación.

2. Siempre buscamos una verdad que es el punto de vista del que resuelve cada situación problemática.

3. Solo investigando el profesor estará en la capacidad de entender los cambios, y de ir a lo par de estos y/o prever el futuro. Si esto no sucede su futuro será la obsolescencia o será un mero repetidor de los conocimientos ajenos.

4. Dentro de la investigación un desafío será la búsqueda del financiamiento.

5. La nueva visión de investigación debe basarse por líneas, grupos de investigación y fuentes tentativas de recursos que respondan a las líneas de investigación.

\section{REFERENCIAS BIBLIOGRÁFICAS}

1. Estándares para la Acreditación de la Carrera Profesional Universitaria de Administración: CONEAU, 2012

2. Guía para la Acreditación de las Carreras Profesionales Universitarias del CONEAU.

3. La Biblia, Evangelio de San Juan.

4. Las Universidades en el Ojo de la Tormenta. EL Comercio. 2012.

5. Periódico Propuesta $\mathrm{N}^{\circ} 106$. Retos de una Nueva Generación: Calidad y Acreditación.

6. Plan para Reestructurar la Investigación en la Escuela de Administración, Documento de Trabajo. 